\title{
Early and late left ventricular effects of breast cancer chemotherapy: a prospective multi-centre study using advanced cardiac imaging
}

\author{
Suchi Grover ${ }^{1,2^{*}}$, Carmine DePasquale ${ }^{1,2}$, Govindarajan Srinivasan ${ }^{1,2}$, Darryl P Leong ${ }^{1}$, Adhiraj Chakrabarty ${ }^{2}$, \\ Kerry A Cheong ${ }^{4}$, Rohit Joshi ${ }^{5}$, Amy Penhall ${ }^{1}$, Majo Joseph', Bogda Koczwara ${ }^{3}$, Joseph Selvanayagam ${ }^{1,2}$
}

From 16th Annual SCMR Scientific Sessions

San Francisco, CA, USA. 31 January - 3 February 2013

\section{Background}

Myocardial dysfunction is a recognized toxicity of anthracycline (A) and herceptin (H) chemotherapy. Whilst there is much current focus on the incidence and magnitude of myocardial dysfunction following the $\mathrm{A} / \mathrm{H}$ regimen, whether these changes are mediated by reversible or irreversible myocardial injury remains unknown. We sought to determine rates of persistent LV dysfunction at 12 months (as defined by left ventricular ejection fraction (LVEF) decrease by $10 \%$ or below lower limits of normal) following $\mathrm{A} / \mathrm{H}$ and explore the mechanism of myocardial dysfunction using advance cardiac imaging.

\section{Methods}

Thirty six chemonaive patients (26 with A, 10 with $\mathrm{H}$ ) with breast cancer, underwent serial CMR imaging (for LV volumes/EF, myocardial edema and necrosis) and advanced echocardiography for global longitudinal strain (GLS) in addition to standard measurements of LV diastolic function. All tests were conducted at baseline, 1, 3 and 12 months (21 patients). Six normal volunteers underwent the same CMR protocol. For edema imaging, short-TI inversion recovery was used in 3 short-axis views of the LV. Myocardial edema was assessed using Lake Louis criteria [1].

\section{Results}

In the study patients, the mean CMR LV end-systolic volume index (LVESVI) increased from baseline of $17.4 \pm$ 6.1 to $26.4 \pm 9.6$; $\mathrm{p}$ value $<0.001$ at 12 months (Table 1 ) .

${ }^{1}$ Flinders Medical Centre, Bedford Park, SA, Australia

Full list of author information is available at the end of the article
LVEF decreased from $72.4 \pm 6.4$ to $64.8 \pm 6.4$ at 12 months; p value $<0.001$. Significant functional changes were seen as early as 1 and 3 months (table 1). Fifty $\%(9 / 21)$ of patients exhibited persistent LV myocardial systolic dysfunction at 12 months. GLS showed no significant change at 1 month, however decreased in absolute magnitude from $-21.2 \pm 3 \%$ baseline to $-19.2 \pm 1.8 \%$ ( $\mathrm{p} \leq$ $0.001)$ at 3 months. Although there was no difference between baseline values of $\mathrm{T} 2$ ratio between normal volunteers and study patients, $52 \%(17 / 33)$ of patients had an abnormal T2 signal as specified by Lake Louis criteria in one or more short axis slices 3 months post chemotherapy. One patient developed new late gadolinium hyperenhancement suggestive of focal myocardial necrosis/fibrosis in the trastuzumab group at 3 months following therapy.

\section{Conclusions}

Our data suggest that the subtle functional changes in the LV myocardium early post breast cancer chemotherapy persist into 12 months in a significant number of patients. These changes are likely mediated by myocardial

\section{Table 1 Functional changes following chemotherapy}

\begin{tabular}{cccccccc}
\hline & LVEDVI & LVESVI & LVEF & LVMM & RVEDVI & RVESVI & RVEF \\
\hline $\begin{array}{c}\text { Baseline } \\
(\mathrm{n}=33)\end{array}$ & $63 \pm 12$ & $17 \pm 6$ & $72 \pm 6$ & $48 \pm 9$ & $66 \pm 14$ & $25 \pm 8$ & $63 \pm 8$ \\
1 month & $64 \pm 11$ & 20 & 69 & $50 \pm 9$ & $69 \pm 15$ & $27 \pm 8^{*}$ & 60 \\
$(\mathrm{n}=33)$ & & $\pm 6^{* *}$ & $\pm 6^{* *}$ & & & & $\pm 6^{*}$ \\
3 months & $65 \pm 12$ & 21 & 68 & $48 \pm 9$ & $67 \pm 13$ & 28 & 58 \\
$(\mathrm{n}=33)$ & & $\pm 7^{* *}$ & $\pm 6^{* *}$ & & & $\pm 7^{* *}$ & $\pm 6^{* *}$ \\
12 months & 73 & 26 & 65 & $40 \pm 6$ & 71 & 35 & 51 \\
$(\mathrm{n}=21)$ & $\pm 14^{* *}$ & $\pm 10^{* *}$ & $\pm 6^{* *}$ & & $\pm 11^{*}$ & $\pm 7^{* *}$ & $\pm 9^{*}$ \\
\hline${ }^{*} \mathrm{p}<0.05{ }^{* *} \mathrm{p}<0.001$ & & & & & &
\end{tabular}


inflammation, and despite absence of irreversible myocardial injury, continue to 12 months post therapy. These findings warrant caution and suggest ongoing regular follow-up of patients following chemotherapy is required.

\section{Funding}

nil.

\section{Author details}

${ }^{1}$ Flinders Medical Centre, Bedford Park, SA, Australia. ${ }^{2}$ Cardiology, Flinders University, Adelaide, SA, Australia. ${ }^{3}$ Oncology, Flinders Medical Centre, Adelaide, SA, Australia. ${ }^{4}$ Adelaide Cancer Centre, Adelaide, SA, Australia. ${ }^{5}$ Oncology Department, Lyell McEwin Hospital, Adelaide, SA, Australia.

Published: 30 January 2013

\section{Reference}

1. Friedrich, et al.. J Am Coll Cardiol 2009, 53(17):1475-87.

doi:10.1186/1532-429X-15-S1-P142

Cite this article as: Grover et al:: Early and late left ventricular effects of breast cancer chemotherapy: a prospective multi-centre study using advanced cardiac imaging. Journal of Cardiovascular Magnetic Resonance 2013 15(Suppl 1):P142.

Submit your next manuscript to BioMed Central and take full advantage of:

- Convenient online submission

- Thorough peer review

- No space constraints or color figure charges

- Immediate publication on acceptance

- Inclusion in PubMed, CAS, Scopus and Google Scholar

- Research which is freely available for redistribution

Submit your manuscript at www.biomedcentral.com/submit 